\title{
Proximale Tibiakopffraktur
}

\author{
Andreas Dávid
}

69-jährige Patientin erleidet durch ein Verdrehtrauma eine proximale Tibiakopffraktur im Jahr 2000.

Röntgenbild nach Unfall (Abb.1): bikondyläre Tibiakopffraktur Typ 41 C2.

Notfallmäßige Versorgung mit medialer T-Platte und 2 von lateral eingebrachten Zugschrauben. Leichter Varusfehler $\left(3^{\circ}\right)$ wurde zunächst hingenommen (Abb. 2).

Röntgenkontrolle nach 4 Wochen (Abb. 3a): sekundäre Dislokation innerhalb von 4 Wochen mit intraartikulärer Schraubenlage.

Indikation zur sekundären Osteosynthese mit leichter geplanter Valgisation durch additive Korrekturosteotomie mit Beckenkammspan (Abb. $\mathbf{3 b}$ ).

Nach 8 Jahren immer noch beschwerdefrei, freie Beweglichkeit trotz radiologischer Arthrosezeichen (Abb. 4).

Fehleranalyse:

1. Fraktur fehlerhaft analysiert. Es handelt sich nicht um eine bikondyläre Tibiakopffraktur, sondern um eine Luxationsfraktur. Dies wird erkennbar an der kompletten Aussprengung der Eminentia intercondylaris und an der lateralen Randfraktur (rim avulsion nach Tilman/Moore).

2. Erste operative Versorgung: Plattenosteosynthese grundsätzlich nicht verkehrt, aber eine stärkere Abstützung muss medial angelegt werden. Eine laterale Achsabweichung ist weniger wahrscheinlich, da die Fibula intakt ist. Die mediale Abstützung in einem eher osteoporotischen Knochen mit einer 2-Schrauben-Fixation ist mechanisch unzureichend. Die mediale Gelenkfläche wird sekundär

OP-JOURNAL 2008; 24: 240

(c) Georg Thieme Verlag KG Stuttgart • New York DOI 10.1055/s-2008-1039091
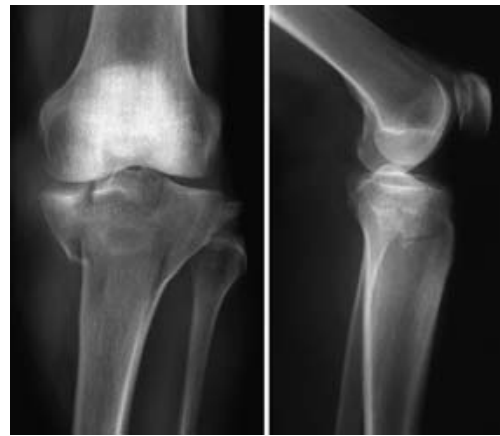

Abb. 1 Unfallbilder.

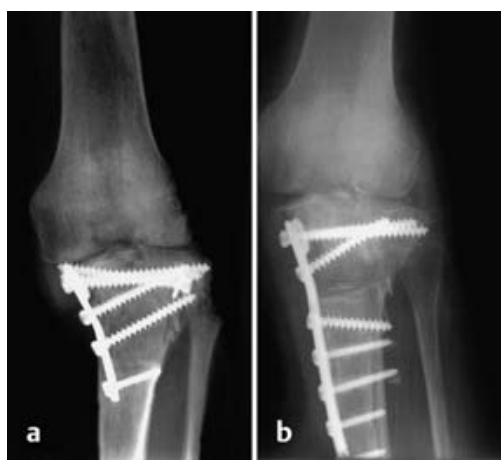

Abb. 3 a und b a A.-p. Aufnahme 4 Wochen nach OP. b 2. Operation, postoperatives Bild.

durch die intraartikulär dislozierte Schraube destruiert.

3. Die Indikation zur Korrekturosteotomie mit Valgisation bei fortschreitender, medial betonter Arthrose ist nicht unbedenklich. Alternativ hätte man zu diesem Zeitpunkt auch eine K-TEP implantieren können (schwierige Technik!).

Fazit

Unkorrekte Diagnose führt zur Verharmlosung des Eingriffs. Die mediale Instabilität ist bedingt durch die initiale unzureichende Plattendimension. Zum Operationszeitpunkt waren winkelstabile Platten noch nicht im Routineeinsatz. Die Fehlerkorrektur ist jedoch richtig und führte in diesem Fall auch zu einem guten Langzeitergebnis.

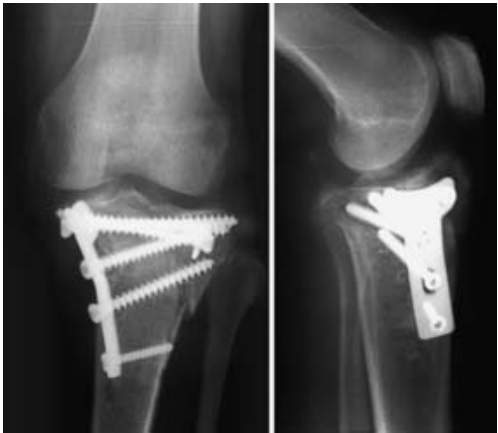

Abb. 2 Postoperative Röntgenbilder.

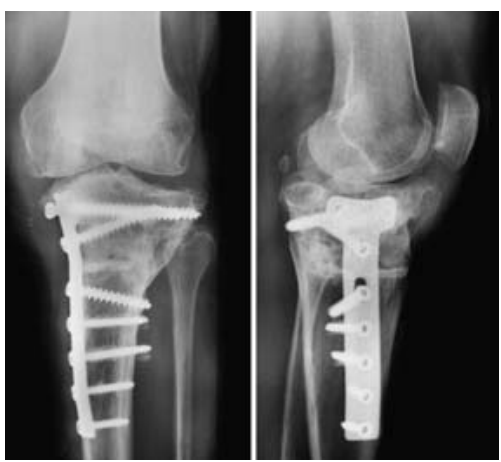

Abb. 4 Röntgen nach 8 Jahren.

Prof. Dr. med. Andreas Dávid Klinikdirektor

Zentrum für Unfall- und Orthopädische Chirurgie HELIOS Klinikum Wuppertal Heusnerstraße 40 42283 Wuppertal

E-Mail: andreas.david@ helios-kliniken.de 